\title{
A new normalisation scheme for normal compression and critical state line for soils
}

\author{
Shambhu S. Sharma ${ }^{1}$ and Mostafa A. Ismail ${ }^{2^{*}}$
}

\section{${ }^{*}$ Correspondence:}

mostafaperth@Gmail.com

2 Prince Sultan University,

Riyadh, Saudi Arabia

Full list of author information

is available at the end of the article

\begin{abstract}
Unlike clays, sands may exist in a virgin condition, but at different initial void ratios. Therefore, there is no consensus in the literature as to the definition of the normal compression line for sands. On the basis of experimental evidence, this paper presents a new simple normalisation scheme to unify the compression response of sands. The normalisation scheme incorporates both the initial void ratio and its corresponding equivalent stress on the limiting compression line as normalising parameters. The novelty of the new normalisation scheme is that it is not only consistent with the framework of critical state soil mechanics, but it is also conceptually in line with recent studies on crushability of soils. The validity of the new normalisation scheme is verified against a wide range of experimental data from isotropic and 1-D compression tests on both sands and clays. It is also shown that a unified compression relationship can be obtained for both clays and sands by taking into account the differences in the compression index at high pressure. Similarities between the compression curves and the critical state line for different soils are also examined, and it is shown that the critical state line for clays and sands can be uniquely represented using the proposed normalisation scheme. Areas for further research, where the new normalisation scheme is deemed valuable, are highlighted.
\end{abstract}

Keywords: Sands, Clays, Triaxial test, Critical state, Compressibility, Normalisation

\section{Introduction}

Critical state soil mechanics (CSSM) has long been regarded as the most suitable unified framework to develop predictive constitutive models for geotechnical problems. The framework, initially developed for reconstituted clay, has been widely used to explain many behavioural aspects of other different geo-materials, such as peat [13], sands [2, $11,22,39]$, weak rocks [7, 38] and hard rocks [15, 32].

Despite the fact that many important contributions have been made in recent years, the suitability of the CSSM framework to describe the behaviour of sand is still debatable [22]. The basis of this debate is that, unlike for reconstituted clay, a sand state depends not only on the stress history but also on the mechanism of deposition (e.g. static stress versus vibration). This means that a sand can exist in a freshly deposited state at any arbitrary formation (initial) void ratio with no difference in its stress history. First loading from any of these initial void ratios leads to irrecoverable (plastic) strain during compression. This raises an important question regarding the uniqueness of the normal compression line (NCL) for sands (e.g. [22]). Indeed many attempts have been made

(c) The Author(s) 2016. This article is distributed under the terms of the Creative Commons Attribution 4.0 International License (http://creativecommons.org/licenses/by/4.0/), which permits unrestricted use, distribution, and reproduction in any medium, provided you give appropriate credit to the original author(s) and the source, provide a link to the Creative Commons license, and indicate if changes were made. 
to define a consistent NCL for sands within the context of CSSM; however, as will be detailed later, this issue has not been resolved satisfactorily.

In an attempt to consistently define the NCL for sands, this paper examines the compression behaviour of sands using experimental results obtained from the literature on different sands subjected to different loading conditions (e.g., isotropic and 1-D compression tests). Based on the experimental results, a new normalisation scheme is proposed to uniquely represent the multitude of compression curves for a sand prepared to different initial densities. Furthermore, the similarities between the isotropic and 1-D compression test results on the one hand and between the NCL and the critical state line (CSL) on the other hand are also examined. Applicability of the proposed normalisation scheme to clays is also verified, and an attempt is made to provide a unified framework to define the NCL for both clays and sands.

Before addressing these issues in detail, it is important to provide a brief background on the compression behaviour of different soils. This is presented in the next few sections.

\section{Background on the compression behaviour of soils}

\section{Typical response}

Figures 1 and 2 show the idealised compression behaviour of reconstituted clays and sands, respectively. These figures illustrate clearly the intrinsic differences in the compression response between the two soils. The virgin state of a clay always lies on a curve that can be uniquely idealised in terms of the slope $\lambda *$ of the compression line, as shown in Fig. 1. However, this simple idealisation cannot be applied to a sand, as it follows more than one compression curve depending on the initial formation density, as shown in Fig. 2.

\section{Definition of the normal compression line for sands}

The difference in the compression response between sands and clays, as observed in Figs. 1 and 2, raises a question regarding what comprises the NCL for sands. Two different propositions for the NCL for sands are available in the literature [22]. The first

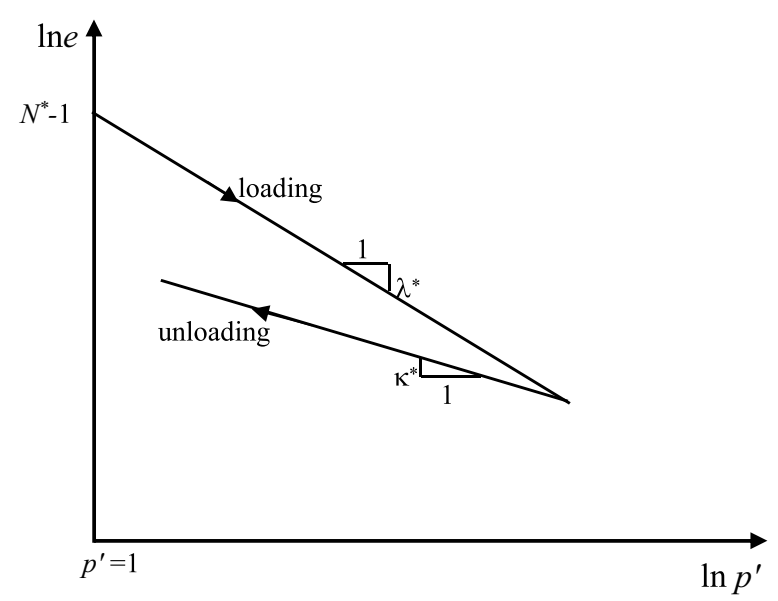

Fig. 1 Idealised compression curves for clays 


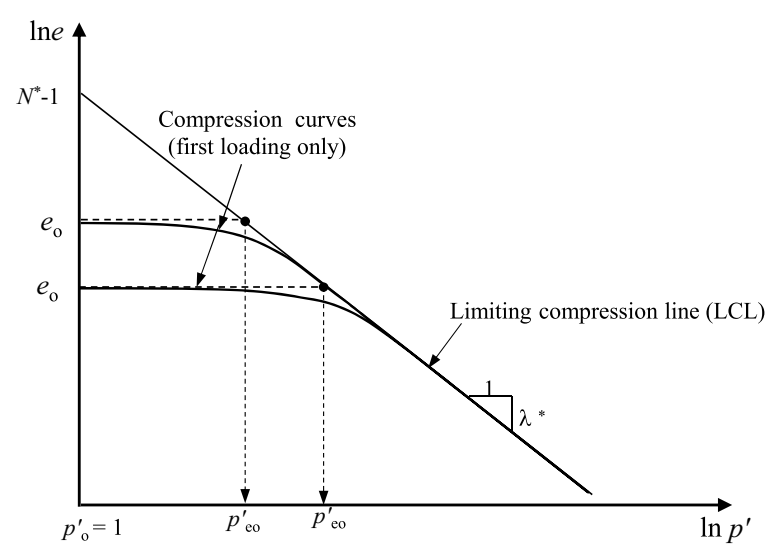

Fig. 2 Idealised compression curves for sands

proposition suggests that, similar to that for clay, the NCL for a sand is unique and it starts only when grain crushing dominates the compression behaviour (e.g. [2, 35]). This is usually referred to as the limiting compression line (LCL), as shown in Fig. 2. On the other hand, following the geological idealisation that any soil experiencing the greatest stress in its history is normally consolidated, the second proposition suggests that the NCL also includes the initial portion of the compression curve before grain crushing becomes dominant. Obviously, this implies existence of an infinite number of normal compression lines for a sand [21,22].

The implications of both these propositions within the context of CSSM are discussed in Jefferies and Been [22]. They argued that, although the first proposition is consistent with the framework of CSSM, it implies that irrecoverable (plastic) strain occurs only from the evolution of the limiting compression curves (i.e. ignoring the plastic strains that occur during initial loading). On the other hand, the implication of the second proposition is that the infinity of the NCLs cannot be defined within the framework of the CSSM. Jefferies and Been [22] attempted to define the infinity of the NCLs for a sand by taking into consideration the volumetric difference between the current state and the CSL-i.e. the state parameter $\Psi$ [4]. However, the general expressions proposed by Jefferies and Been [22] are rather complicated, limited to low stress levels before grain crushing dominates the compression behaviour, and require a large number of experimental results to validate them. Moreover, the general applicability of their framework to different sands needs to be confirmed through further investigations.

To this end, it is obvious that within the context of the CSSM, neither of the two propositions for the NCL discussed above satisfactorily describes the overall features of the compression behaviour of sand. In general, application of first proposition is limited to the high stress range, whereas the second proposition is limited to the low stress range. A satisfactory definition of the NCL should be able to capture the compression response in both the low and high stress ranges. In addition, it should be consistent for both clays and sands, so that the observed compression behaviour for different soils can be duly idealised. This paper proposes a new normalisation scheme so that compression behaviour of different soils can be consistently described. However, first, the overall 
importance of normalisation, and the different existing normalisation schemes used in the literature, are discussed in the following section.

\section{Mathematical representation of the normal compression line (NCL)}

Within the context of the CSSM, the NCL for a soil is often represented assuming a linear relationship between the void ratio $e$ and logarithm of the effective stress $\sigma^{\prime}$ as:

$$
e-e_{r e f}=-\lambda \ell n \sigma^{\prime}
$$

where $e_{r e f}$ is the reference void ratio (often defined as the void ratio corresponding to an effective stress of unity), $\lambda$ is the slope of the normal compression line in $e-\ln \sigma^{\prime}$ space (or $\lambda^{*}$ in $\ell$ ne $-\ell$ n $\sigma^{\prime}$ space), and $\sigma^{\prime}$ is the effective stress (i.e. vertical effective stress $\sigma_{\mathrm{v}}^{\prime}$ for 1-D compression and mean effective stress $p^{\prime}$ for isotropic compression). Although Eq. (1) has been extensively used (e.g. [2, 35]), it is dimensionally inconsistent. Ironically, in their original paper, Roscoe et al. [43] presented the normal compression line in a dimensionless form as:

$$
e-e_{r e f}=-\lambda \ell n\left(\frac{\sigma^{\prime}}{\sigma_{o}^{\prime}}\right)
$$

Roscoe et al. [43] define $\sigma_{\mathrm{o}}^{\prime}$ as the effective stress corresponding to $e_{\text {ref }}$ It has been widely argued (e.g. [6, 40]) that, although Eq. (2) provides a dimensionally consistent relationship, its use to represent the compression behaviour is still limited, mainly because:

1. at high pressure most soils show non-linear compression behaviour in an $e-\ln \sigma^{\prime}$ plot;

2. when $\sigma^{\prime}>\sigma_{o}^{\prime} \exp \left(e_{\text {ref }} / \lambda\right)$, Eq. (2) predicts a negative void ratio.

In an attempt to provide a more general and accurate representation of the normal consolidation line for a soil over a wide stress range, Pestana [40] proposed that the normal compression line NCL (or limiting compression line LCL for sand) can be better represented as:

$$
\ln \left(\frac{e}{e_{r e f}}\right)=-\lambda^{*} \ln \left(\frac{\sigma^{\prime}}{\sigma_{o}^{\prime}}\right)
$$

where $\lambda^{*}$ is the slope of the normal compression line in $\ell n e-\ell n \sigma^{\prime}$ plot. It is to be noted that the suffix * is used here to differentiate it from $\lambda$ obtained from an $e$-ln $\sigma^{\prime}$ plot.

The above discussions clarify that, although it was realised in the early development of the CSSM [43] that the compression response should be presented in a normalised stress plot [as in Eqs. (2) or (3)], it is surprising to note that no attempt has been made to define a proper normalising parameter for the compression behaviour of soils. In fact it is evident from many later publications that even the importance of the stress normalisation is often ignored (e.g. [2, 35]). This is mainly because most of the research on the CSSM was limited to clay, where the NCL is always assumed to be unique. In this case, the role of stress normalisation is merely to offset the NCL. However, in the case of sand, where a multitude of NCLs exist, proper normalisation is definitely be valuable. 


\section{Proposal for a new normalisation scheme}

In an attempt to define a unique NCL for all soils, a new normalisation scheme is proposed in this paper. The proposed normalisation scheme consists of the following three elements:

1. Determination of the compression index $\left(\lambda^{*}\right)$ and normalising stress $\left(\sigma_{\mathrm{eo}}^{\prime}\right)$, which is determined from mapping the initial void ratio $\left(e_{0}\right)$ onto the LCL as shown in Fig. 2. It should be noted that $\lambda$ (or $\phi$-slope of the normal compression in $\ln v-\ln p^{\prime}$ plot, [6]) can be used instead of $\lambda^{*}$, but steps 2 and 3 below should be modified accordingly.

2. Representation of the compression curves for sand (with different initial densities) in a normalised plot in $e / e_{\mathrm{o}}$ versus $\left(\sigma^{\prime}-\sigma_{\mathrm{o}}^{\prime}\right) / \sigma_{\mathrm{eo}}^{\prime}$ space, where $e$ and $\sigma^{\prime}$ are the current void ratio and stress, respectively, and $\sigma_{\mathrm{o}}^{\prime}$ is the effective stress corresponding to $e_{\mathrm{o}}$ as shown in Fig. 2 (in this paper $\sigma_{\mathrm{o}}^{\prime}$ is considered as unity).

3. Representation of the compression curves for different soils in a normalised plot by taking into consideration the differences in $\lambda^{*}$ between different soils-i.e. a plot of $\left(1 / \lambda^{*}\right) \ln \left(e / e_{\mathrm{o}}\right) \operatorname{versus}\left(\sigma^{\prime}-\sigma_{\mathrm{o}}^{\prime}\right) / \sigma_{\mathrm{eo}}^{\prime}$

This simple normalisation scheme will be examined against a large number of experimental results obtained from both sands and clays, but a brief background on the experimental database is presented first.

\section{Details of the experimental database}

Sand samples from different origins covering a wide range of initial void ratio $\left(e_{\mathrm{o}}\right)$ and compression parameters $\lambda^{*}$ and $N^{*}$ were examined as summarised in Tables 1, 2 and 3; where $\lambda^{*}$ and $N^{*}$ are the slope and intercept of the LCC in $\ln e-\ln p^{\prime}$ plot as shown in Fig. 2. (It should be noted that the derivation of these parameters for sands requires tests to be performed to high stress). The maximum stress values $\sigma_{\max }^{\prime}: p_{\max }^{\prime}$ for isotropic tests and $\sigma_{\mathrm{v} \text { max }}^{\prime}$ for 1-D tests) reached in each test are also reported in Tables 1, 2 and 3. Results obtained from both isotropic and 1-D compression tests were used. The experimental database on the compression response of different clays and the CSL for different soils are presented in Tables 4 and 5, respectively. (Note that most of the test results were collected from the published literature, and only a few tests were performed by the authors). Additional details on the soil properties can be found in the relevant references listed in Tables 1, 2, 3, 4 and 5, and hence are not discussed here.

\section{Experimental validation of the new normalisation scheme for different sands}

Application of the new normalisation scheme to the experimental data presented above led to the results shown in Figs. 3, 4 and 5 in the normalised $\left(1 / \lambda^{*}\right) \ln \left(e / e_{\mathrm{o}}\right)$ versus $\left(\sigma^{\prime}-\sigma_{\mathrm{o}}^{\prime}\right) / \sigma_{\text {eo }}^{\prime}$ space. It should be noted that the samples were tested at different initial void ratios as reported in Tables 3, 4 and 5. Figure 3 presents results from 31 individual isotropic compression tests on 15 different types of sands. Similarly, results obtained from 44 individual anisotropic compression tests on 16 different types of sands are presented in Fig. 4 and additional results obtained from 1-D compression tests [8] are shown in Fig. 5. [Each soil in Figs. 3, 4 and 5 was given a different symbol and the soil name (soil ID) reported in the legend of each figure is in accordance with the soil ID 
Table 1 Database of isotropic compression tests for different sands

\begin{tabular}{|c|c|c|c|c|c|c|c|}
\hline S. no & Soil & Soil ID & $p_{\max }^{\prime}(\mathrm{MPa})$ & $e_{\mathrm{o}}$ & $N^{*}$ & $\lambda^{*}$ & References \\
\hline \multirow[t]{2}{*}{1} & Aio & $\mathrm{AO}$ & 10.00 & 0.760 & 17.09 & 0.28 & Hyodo et al. [19] \\
\hline & & & 10.12 & 0.652 & & & \\
\hline 2 & Chattachooche river & $\mathrm{CHA}$ & 63.01 & 0.723 & 35.48 & 0.34 & Vesic and Clough [48] \\
\hline 3 & Chiibashi & $\mathrm{CHI}$ & 41.00 & 1.044 & 45.92 & 0.35 & Kato et al. [24] \\
\hline \multirow[t]{3}{*}{4} & Dogs Bay & $\mathrm{DB}$ & 7.98 & 1.709 & 62.68 & 0.37 & Coop [11] \\
\hline & & & 7.26 & 1.633 & & & \\
\hline & & & 7.63 & 1.444 & & & \\
\hline 5 & North Rankin & NR & 65.56 & 1.120 & 85.75 & 0.42 & Huang [17] \\
\hline 6 & Goodwyn & GW & 10.19 & 1.740 & 72.97 & 0.39 & Sharma [45] \\
\hline \multirow[t]{3}{*}{7} & Ham river & $\mathrm{HR}$ & 8.85 & 0.799 & 55.02 & 0.36 & Sharma [45] \\
\hline & & & 47.71 & 0.692 & & & \\
\hline & & & 18.47 & 0.689 & & & \\
\hline \multirow[t]{3}{*}{8} & Ledge point & $L P$ & 10.00 & 1.074 & 20.82 & 0.25 & Sharma [45] \\
\hline & & & 14.20 & 0.974 & & & \\
\hline & & & 14.30 & 0.901 & & & \\
\hline 9 & Masado & MA & 41.65 & 0.902 & 4.89 & 0.15 & Kato et al. [24] \\
\hline 10 & Rottnest & RT & 56.08 & 0.940 & 65.17 & 0.38 & Ismail [20] \\
\hline \multirow[t]{4}{*}{11} & Sacramento river & SAR & 13.97 & 0.870 & 20.02 & 0.37 & Lee and Seed [27] \\
\hline & & & 12.88 & 0.778 & & & \\
\hline & & & 14.13 & 0.711 & & & \\
\hline & & & 14.42 & 0.608 & & & \\
\hline \multirow[t]{3}{*}{12} & Shirasu & $\mathrm{SHI}$ & 40.43 & 1.289 & 32.07 & 0.31 & Hyodo et al. [19] \\
\hline & & & 42.61 & 1.143 & & & \\
\hline & & & 3.05 & 0.922 & & & \\
\hline 13 & Silica 1.4-1.8 & $\mathrm{SI} 1$ & 40.11 & 0.647 & 34.52 & 0.43 & Kato et al. [24] \\
\hline 14 & Silica 1.8-2.0 & $\mathrm{SI} 2$ & 39.45 & 0.620 & 36.74 & 0.34 & Kato et al. [24] \\
\hline \multirow[t]{5}{*}{15} & Toyoura & TO & 3.97 & 0.908 & 24.49 & 0.37 & Miura et al. [33] \\
\hline & & & 18.75 & 0.840 & & & \\
\hline & & & 48.68 & 0.770 & & & \\
\hline & & & 3.93 & 0.610 & & & \\
\hline & & & 53.70 & 0.590 & & & \\
\hline
\end{tabular}

$p_{\max }^{\prime}$ is the maximum mean effective stress applied during consolidation

listed in the corresponding table; soil ID in Figs. 3, 4 and 5 corresponds to Tables 1, 2 and 3 , respectively].

It is encouraging to note from Fig. 3 that a reasonably unique isotropic normal compression line exists for different sands covering a wide range of initial void ratios and compression characteristics. A similar pattern can be observed from the anisotropic compression test results presented in Figs. 4 and 5.

Direct comparison of the results from the isotropic and anisotropic compression tests results presented in Figs. 3, 4 and 5 is shown in Fig. 6 in terms of $\left(1 / \lambda^{*}\right) \ln \left(e / e_{\mathrm{o}}\right)$ versus $\left(\sigma^{\prime}-\sigma_{\mathrm{o}}^{\prime}\right) / \sigma_{\mathrm{eo}}^{\prime}$, where $\sigma^{\prime}$ is the effective stress and is equal to $\sigma_{\mathrm{v}}^{\prime}$ for 1-D compression tests and $p^{\prime}$ for isotropic compression tests. It can be concluded from Figs. 3, 4, 5 and 6 that a reasonably unique normalised NCL exists for all sands, irrespective of their initial void ratio, origin (mineralogy) and the type of test. In other words, the differences in the compression response between different sands tested under different loading conditions lie in the differences in the compression parameters $\lambda^{*}$ and $N^{*}$. 
Table 2 Database of 1-D compression tests for different sands

\begin{tabular}{|c|c|c|c|c|c|c|c|}
\hline S. no & Soil & Soil ID & $\sigma_{\mathrm{v} \text { max }}^{\prime}(\mathrm{MPa})$ & $e_{\mathrm{o}}$ & $N^{*}$ & $\lambda^{*}$ & References \\
\hline \multirow[t]{3}{*}{1} & Cambria sand & $\mathrm{CM}$ & 816.00 & 0.696 & 93.77 & 0.432 & Yamamuro et al. [49] \\
\hline & & & 805.14 & 0.599 & & & \\
\hline & & & 838.90 & 0.549 & & & \\
\hline \multirow[t]{4}{*}{2} & Glauconite sand & $\mathrm{GL}$ & 28.92 & 0.835 & 158.90 & 0.463 & As reported in Pestana [40] \\
\hline & & & 32.33 & 0.765 & & & \\
\hline & & & 44.67 & 0.632 & & & \\
\hline & & & 38.80 & 0.614 & & & \\
\hline 3 & Ground dolomite-1 & GD1 & 142.94 & 0.984 & 64.99 & 0.400 & Roberts [42] (as reported in [40]) \\
\hline 4 & Ground dolomite-2 & GD2 & 70.66 & 0.792 & 76.81 & 0.432 & \\
\hline \multirow[t]{3}{*}{5} & Ground feldspar & GF & 144.56 & 1.104 & 61.39 & 0.379 & Roberts [42] (as reported in [40]) \\
\hline & & & 141.55 & 1.079 & & & \\
\hline & & & 112.20 & 0.926 & & & \\
\hline 6 & Ground quartz-1 & GQ1 & 141.13 & 1.052 & 54.25 & 0.372 & Roberts [42] (as reported in [40]) \\
\hline 7 & Ground quartz-2 & GQ2 & 138.22 & 0.829 & 62.17 & 0.394 & \\
\hline \multirow[t]{3}{*}{8} & Gypsum sand & GY & 790.00 & 0.774 & 172.24 & 0.535 & Yamamuro et al. [49] \\
\hline & & & 802.00 & 0.715 & & & \\
\hline & & & 790.84 & 0.674 & & & \\
\hline \multirow[t]{2}{*}{9} & Hawaiian sand & $\mathrm{HS}$ & 138.29 & 0.833 & 80.66 & 0.397 & Roberts [42] (as reported in [40]) \\
\hline & & & 174.72 & 0.726 & & & \\
\hline \multirow[t]{4}{*}{10} & Hokksund sand & HK & 24.13 & 0.754 & 68.66 & 0.391 & As reported in Pestana [40] \\
\hline & & & 24.13 & 0.715 & & & \\
\hline & & & 49.40 & 0.547 & & & \\
\hline & & & 49.40 & 0.530 & & & \\
\hline \multirow[t]{3}{*}{11} & Ottawa & OT & 138.04 & 0.821 & 245.99 & 0.465 & DeSouza [14] (as reported in [40]) \\
\hline & & & 141.25 & 0.763 & & & \\
\hline & & & 136.91 & 0.673 & & & \\
\hline \multirow[t]{3}{*}{12} & Quiu sand & QU & 23.21 & 0.999 & 25.04 & 3.220 & As reported in Pestana [40] \\
\hline & & & 23.47 & 0.903 & & & \\
\hline & & & 48.44 & 0.822 & & & \\
\hline \multirow[t]{2}{*}{13} & Quartz sand & QT & 808.71 & 0.899 & 79.39 & 0.383 & Yamamuro et al. [49] \\
\hline & & & 798.16 & 0.679 & & & \\
\hline \multirow[t]{5}{*}{14} & Sangamon river & SAN & 19.22 & 0.800 & 32.61 & 0.288 & DeSouza [14] (as reported in [40]) \\
\hline & & & 19.26 & 0.758 & & & \\
\hline & & & 19.14 & 0.715 & & & \\
\hline & & & 19.17 & 0.656 & & & \\
\hline & & & 19.19 & 0.630 & & & \\
\hline \multirow[t]{3}{*}{15} & Ticino sand & $\mathrm{Tl}$ & 48.08 & 0.799 & 69.21 & 0.392 & Hendron [16] (as reported in [40]) \\
\hline & & & 47.59 & 0.676 & & & \\
\hline & & & 49.15 & 0.602 & & & \\
\hline \multirow[t]{5}{*}{16} & Wabash river sand & WR & 19.09 & 0.675 & 36.83 & 0.329 & Hendron [16] (as reported in [40]) \\
\hline & & & 19.09 & 0.630 & & & \\
\hline & & & 19.27 & 0.572 & & & \\
\hline & & & 19.14 & 0.545 & & & \\
\hline & & & 19.09 & 0.502 & & & \\
\hline
\end{tabular}

$\sigma_{\mathrm{v} \text { max }}^{\prime}$ is the maximum vertical effective stress applied during consolidation

\section{Compression response for clays}

It is now interesting to examine the compression response of clays in a manner similar to that discussed above for sands; the aim is to investigate whether a unified trend will 
Table 3 Database of 1-D compression tests for different sands (results from [8])

\begin{tabular}{|c|c|c|c|c|c|c|c|}
\hline S. no & Soil & Soil ID & $D_{60}(\mathrm{~mm})$ & $\sigma_{\mathrm{v} \max }^{\prime}(\mathrm{MPa})$ & $e_{\mathrm{o}}$ & $N^{*}$ & $\lambda^{*}$ \\
\hline 1 & Mono-quartz-rich-1 & MQ-1 & 0.33 & 49.41 & 0.810 & 152.12 & 0.45 \\
\hline 2 & Mono-quartz-rich-2 & MQ-2 & 2.30 & 48.66 & 0.733 & 144.76 & 0.50 \\
\hline 3 & Mono-quartz-rich-3 & MQ-3 & 1.51 & 47.88 & 0.744 & 177.29 & 0.50 \\
\hline 4 & Mono-quartz-rich-4 & MQ-4 & 0.85 & 50.28 & 0.758 & 145.78 & 0.47 \\
\hline 5 & Mono-quartz-rich-5 & MQ-5 & 0.71 & 50.66 & 0.735 & 160.07 & 0.47 \\
\hline 6 & Mono-quartz-rich-6 & MQ-6 & 0.33 & 50.77 & 0.751 & 138.98 & 0.44 \\
\hline 7 & Mono-quartz-rich-7 & MQ-7 & 0.19 & 49.23 & 0.734 & 23.43 & 0.26 \\
\hline 8 & Mono-quartz-rich-8 & MQ-8 & 0.10 & 48.58 & 0.746 & 64.43 & 0.36 \\
\hline 9 & Mono-quartz-rich-9 & MQ-9 & 0.19 & 50.13 & 0.893 & 83.88 & 0.38 \\
\hline 10 & Mono-quartz-rich-10 & MQ-10 & 0.38 & 49.28 & 0.869 & 122.57 & 0.44 \\
\hline 11 & Mono-quartz-rich-11 & MQ-11 & 0.71 & 49.81 & 0.747 & 100.59 & 0.46 \\
\hline 12 & Mono-quartz-rich-12 & MQ-12 & 0.1 & 53.87 & 0.923 & 48.24 & 0.33 \\
\hline 13 & Mono-quartz-rich-13 & MQ-13 & 0.1 & 52.48 & 0.751 & 25.84 & 0.27 \\
\hline 14 & Mono-quartz-rich (SR) & MQR & 0.17 & 49.51 & 0.906 & 62.25 & 0.34 \\
\hline 15 & Mono-quartz-rich (SA) & MQA & 0.19 & 48.32 & 0.891 & 82.65 & 0.38 \\
\hline 16 & Quartz (mixed-1) & QM-1 & - & 47.04 & 0.808 & 109.02 & 0.43 \\
\hline 17 & Quartz (mixed-2) & QM-2 & 0.33 & 48.68 & 0.809 & 115.84 & 0.43 \\
\hline 18 & Quartz (mixed-3) & QM-3 & - & 40.86 & 0.696 & 29.73 & 0.34 \\
\hline 19 & Lithic-1 & $\mathrm{LI}-1$ & 1.46 & 50.60 & 0.885 & 143.87 & 0.48 \\
\hline 20 & Lithic-2 & $\mathrm{LI}-2$ & 0.72 & 52.31 & 0.869 & 176.87 & 0.49 \\
\hline 21 & Lithic-3 & LI-3 & 0.37 & 48.05 & 0.866 & 141.43 & 0.45 \\
\hline 22 & Lithic-4 & LI-4 & 0.17 & 50.60 & 0.882 & 108.17 & 0.42 \\
\hline 23 & Lithic-5 & LI-5 & 0.17 & 49.81 & 0.870 & 89.01 & 0.40 \\
\hline 24 & Lithic-6 & LI-6 & 0.37 & 47.52 & 0.891 & 130.99 & 0.45 \\
\hline 25 & Lithic-7 & $\mathrm{LI}-7$ & 0.72 & 48.86 & 0.776 & 103.34 & 0.44 \\
\hline 26 & Lithic-8 & LI-8 & 1.46 & 48.56 & 0.758 & 107.77 & 0.46 \\
\hline 27 & Carbonate-1 & CA-1 & 1.48 & 40.60 & 1.190 & 139.41 & 0.47 \\
\hline 28 & Carbonate-2 & CA-2 & 0.75 & 47.99 & 1.165 & 130.16 & 0.46 \\
\hline 29 & Carbonate-3 & CA-3 & 0.38 & 49.23 & 1.178 & 140.63 & 0.46 \\
\hline 30 & Carbonate-4 & CA-4 & 0.19 & 47.12 & 1.171 & 130.44 & 0.44 \\
\hline 31 & Carbonate-5 & CA-5 & 0.19 & 50.00 & 0.870 & 101.68 & 0.42 \\
\hline 32 & Carbonate-6 & CA-6 & 0.38 & 49.87 & 0.867 & 138.28 & 0.45 \\
\hline 33 & Carbonate-7 & CA-7 & 0.75 & 49.00 & 1.037 & 167.72 & 0.48 \\
\hline 34 & Carbonate-8 & CA-8 & 1.48 & 1.36 & 1.200 & 189.07 & 0.50 \\
\hline 35 & Carbonate-9 & CA-9 & 0.75 & 49.16 & 1.409 & 265.89 & 0.54 \\
\hline 36 & Carbonate-10 & CA-10 & 2.8 & 50.93 & 1.652 & 349.29 & 0.56 \\
\hline 37 & Carbonate-11 & CA-11 & 2.8 & 49.65 & 1.402 & 318.56 & 0.56 \\
\hline 38 & Carbonate-12 & CA-12 & 0.75 & 51.34 & 1.157 & 179.07 & 0.49 \\
\hline 39 & Carbonate-13 & CA-13 & 0.75 & 50.45 & 1.032 & 206.75 & 0.50 \\
\hline 40 & Carbonate-14 & CA-14 & 0.19 & 50.45 & 1.178 & 156.49 & 0.46 \\
\hline 41 & Carbonate-15 & CA-15 & 0.19 & 50.93 & 0.871 & 141.17 & 0.45 \\
\hline 41 & Chirt-rich & $\mathrm{CH}$ & 1.67 & 49.31 & 0.717 & 54.82 & 0.34 \\
\hline
\end{tabular}

$S R$ sub rounded, $S A$ sub angular

emerge for both sands and clays whose compression behaviour has always been treated separately in the literature. To this end, a large number of experimental results obtained from different clays were also examined, using the database listed in Table 4 for clays. 
Table 4 Isotropic and 1-D compression test results for different clays

\begin{tabular}{|c|c|c|c|c|c|c|c|}
\hline S. no & Soil & Soil ID & $p_{\max }^{\prime}(\mathrm{MPa})$ & $e_{\mathrm{o}}$ & $N^{*}$ & $\lambda^{*}$ & References \\
\hline \multicolumn{8}{|c|}{ Isotropic compression tests } \\
\hline 1 & Black cotton & $\mathrm{BC}$ & 0.81 & 4.219 & 5.22 & 0.198 & Nagaraj and Srinivasa Murthy [37] \\
\hline 2 & Boston blue & BB-1 & 0.79 & 3.060 & 4.06 & 0.180 & Taylor [47] \\
\hline 3 & Chicago & CG & 1.61 & 4.033 & 5.03 & 0.227 & Taylor [47] \\
\hline 4 & Drammen (plastic) & $\mathrm{DP}$ & 0.81 & 3.666 & 4.67 & 0.223 & Butterfield [6] \\
\hline 5 & Drammen (lean) & $\mathrm{DL}$ & 0.69 & 1.655 & 2.65 & 0.135 & Butterfield [6] \\
\hline 6 & Kaolin & $\mathrm{KA}-1$ & 0.69 & 4.400 & 5.40 & 0.193 & Amerasinghe [1] \\
\hline 7 & Litle belt & LB & 0.78 & 5.014 & 6.01 & 0.186 & Hvorslev [18] \\
\hline 8 & Newfoundland & NS & 1.66 & 3.064 & 4.06 & 0.193 & Taylor [47] \\
\hline 9 & Newfoundland & NP & 0.80 & 61.614 & 62.61 & 0.418 & Taylor [47] \\
\hline 10 & Red soil & $\mathrm{RC}$ & 0.78 & 1.557 & 2.56 & 0.150 & Nagaraj and Srinivasa Murthy [37] \\
\hline 11 & residual soil & RS & 0.78 & 1.899 & 2.90 & 0.133 & Leonards and Ramiah [28] \\
\hline 12 & Sail soil & $\mathrm{SI}$ & 0.82 & 6.295 & 7.29 & 0.182 & Nagaraj and Srinivasa Murthy [37] \\
\hline 13 & Soft clay & $\mathrm{SO}$ & 0.79 & 3.281 & 4.28 & 0.178 & Nagaraj and Srinivasa Murthy [37] \\
\hline 14 & silty clay & SC-1 & 0.80 & 2.459 & 3.46 & 0.156 & Nagaraj and Srinivasa Murthy [37] \\
\hline 15 & silty clay & SC-2 & 0.80 & 1.152 & 2.15 & 0.125 & Jennings and Burland [23] \\
\hline 16 & Silty clay & SC-3 & 0.80 & 1.750 & 2.75 & 0.128 & Jennings and Burland [23] \\
\hline 17 & Vienna & $\mathrm{Vl}$ & 0.79 & 1.685 & 2.69 & 0.146 & Hvorslev [18] \\
\hline 18 & Weald & WD & 0.56 & 4.098 & 5.10 & 0.373 & Roscoe et al. [43] \\
\hline 19 & Whangamarino & WG & 0.79 & 4.851 & 5.85 & 0.152 & Nagaraj and Srinivasa Murthy [37] \\
\hline \multicolumn{8}{|c|}{ 1-D compression tests } \\
\hline 1 & Argile plastique & AP & 2.01 & 4.906 & 5.91 & 0.227 & Burland [5] \\
\hline 2 & Boston blue & BB-2 & 100.00 & 2.224 & 3.22 & 0.175 & Pestana [40] \\
\hline 3 & Bothkennear & BT & 0.99 & 3.103 & 4.10 & 0.196 & Smith et al. [46] \\
\hline 4 & Detroit & DT & 27.17 & 1.738 & 2.74 & 0.190 & Lambe and Whitman [26] \\
\hline 5 & Hiroshima & $\mathrm{HI}$ & 1.26 & 3.852 & 4.85 & 0.211 & Moriwaki et al. [34] \\
\hline 6 & Horten & $\mathrm{HO}$ & 1.04 & 1.144 & 2.14 & 0.143 & Lambe and Whitman [26] \\
\hline 7 & Kaolin & $\mathrm{KA}-2$ & 0.51 & 5.373 & 6.37 & 0.199 & Nadarajah [36] \\
\hline 8 & Kleinbelt Ton & $\mathrm{KT}$ & 1.06 & 5.373 & 6.37 & 0.204 & Burland [5] \\
\hline 9 & Kurashiki & $\mathrm{KU}$ & 1.39 & 2.795 & 3.80 & 0.191 & Moriwaki et al. [34] \\
\hline 10 & London & LC & 4.66 & 3.276 & 4.28 & 0.222 & Burland [5] \\
\hline 11 & Lower cromer & LT & 1.01 & 0.974 & 1.97 & 0.151 & Burland [5] \\
\hline 12 & Magnus & MG & 3.99 & 1.789 & 2.79 & 0.193 & Burland [5] \\
\hline 13 & Maizuru & $M Z$ & 1.29 & 4.283 & 5.28 & 0.221 & Moriwaki et al. [34] \\
\hline 14 & Mexico city & $M C$ & 2.84 & 42.606 & 43.61 & 0.362 & Mesri et al. [31] \\
\hline 15 & Shellhaven & SL & 0.61 & 3.609 & 4.61 & 0.187 & Lambe and Whitman [26] \\
\hline 16 & Tilbury & $\mathrm{Tl}$ & 0.16 & 4.608 & 5.61 & 0.205 & Lambe and Whitman [26] \\
\hline 17 & Wiener Tegel & WT & 1.04 & 1.761 & 2.76 & 0.162 & Burland [5] \\
\hline
\end{tabular}

Figure 7 shows the normalised compression lines for all the clays reported in Table 4 . Indeed, the new normalisation scheme reasonably unifies the normal compression lines for the wide range of clays examined.

\section{Unified compression curves for sands and clays}

It is shown in the previous sections that the compression behaviour of different sands and clays (separately) can be uniquely represented using the new normalisation scheme. An obvious step forward thus would be to directly compare the compression response of 
Table 5 Database on critical state line for different soils

\begin{tabular}{|c|c|c|c|c|c|c|c|}
\hline S. no & Soil & Soil ID & $p_{\max }^{\prime}(\mathrm{MPa})$ & $e_{\mathrm{o}}$ & $\Gamma^{*}$ & $\lambda^{*}$ & References \\
\hline \multicolumn{8}{|l|}{ Clays } \\
\hline 1 & Kaolin & KAC & 0.70 & 3.149 & 4.15 & 0.159 & Schofield and Wroth [44] \\
\hline 2 & Klein Belt & $\mathrm{KBC}$ & 0.70 & 4.378 & 5.38 & 0.180 & Schofield and Wroth [44] \\
\hline 3 & London & LNc & 0.70 & 2.014 & 3.01 & 0.158 & Schofield and Wroth [44] \\
\hline 4 & Wiener & Wlc & 0.70 & 1.640 & 2.64 & 0.168 & Schofield and Wroth [44] \\
\hline 5 & Weald & WEC & 0.60 & 3.410 & 4.41 & 0.370 & Roscoe et al. [43] \\
\hline \multicolumn{8}{|l|}{ Sands } \\
\hline 1 & Chattachooche river & $\mathrm{CRC}$ & 19.12 & 0.944 & 23.82 & 0.440 & Muir Wood [35] \\
\hline 2 & Chiibashi & $\mathrm{CHC}$ & 10.04 & 1.319 & 12.45 & 0.350 & Kato et al. [24] \\
\hline 3 & Dogs Bay & $\mathrm{DBC}$ & 6.94 & 1.733 & 13.97 & 0.371 & Coop [11] \\
\hline 4 & Erksak & ERc & 2.81 & 0.772 & 10.55 & 0.350 & Been et al. [3] \\
\hline 5 & Ham river & HRc & 56.05 & 0.900 & 14.24 & 0.360 & Coop and Lee [10] \\
\hline 6 & Leighton Buzzard & $\angle B C$ & 4.79 & 0.969 & 4.72 & 0.200 & Been et al. [3] \\
\hline 7 & Masado & MSC & 61.68 & 0.729 & 2.49 & 0.148 & Kato et al. [24] \\
\hline 8 & Massey tunnel & MTc & 1.00 & 1.094 & 7.23 & 0.298 & Konrad [25] \\
\hline 9 & Quebec & $\mathrm{QBC}$ & 1.12 & 0.750 & 9.15 & 0.389 & Konrad [25] \\
\hline 10 & Sacramento river & SRC & 18.55 & 0.951 & 16.25 & 0.387 & Riemer et al. [41], Lee and Seed [27] \\
\hline 11 & Silica 1.4-1.7 & SIC-1 & 75.95 & 0.841 & 17.21 & 0.433 & Kato et al. [24] \\
\hline 12 & Silica 1.8-2.0 & Slc-2 & 34.94 & 0.759 & 9.21 & 0.340 & Kato et al. [24] \\
\hline 13 & Ticino & TlC & 1.11 & 0.910 & 9.66 & 0.365 & Konrad [25] \\
\hline 14 & Toyoura & TOC & 35.49 & 0.926 & 17.98 & 0.376 & Miura et al. [33] \\
\hline 15 & Tung-Chung & TCC & 0.70 & 0.870 & 4.62 & 0.253 & Li and Wang [29] \\
\hline \multicolumn{8}{|c|}{ Other soils } \\
\hline 1 & Johnstone & JTC & 50.00 & 0.580 & 8.80 & 0.335 & Novello and Johnston [38] \\
\hline 2 & Ohya tuff & OTC & 50.00 & 0.860 & 4.56 & 0.197 & Novello and Johnston [38] \\
\hline
\end{tabular}
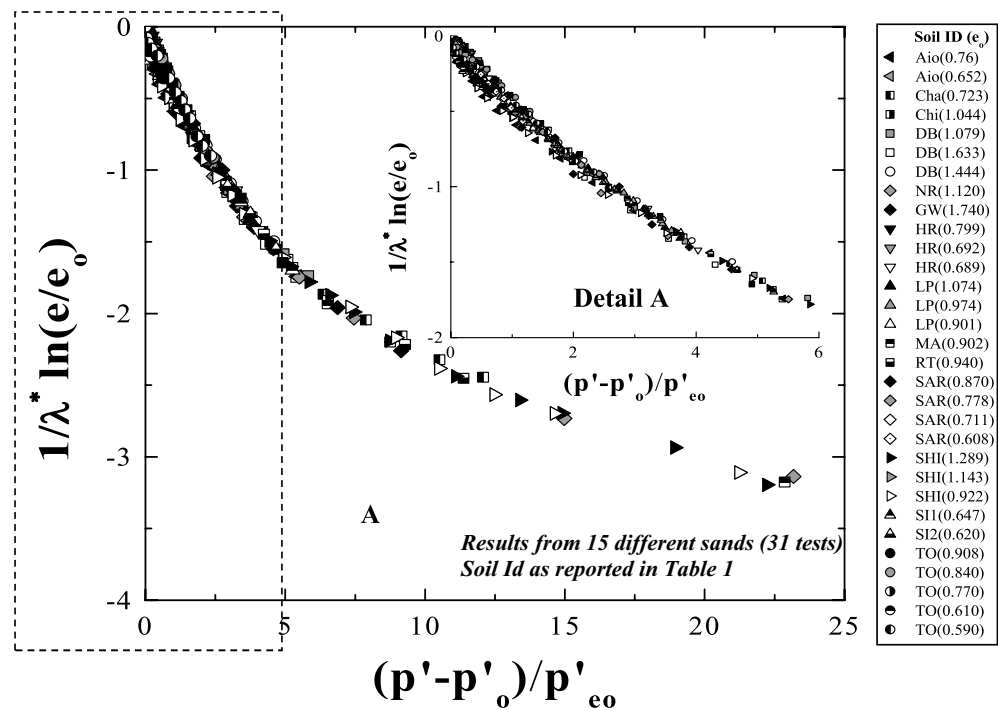

Fig. 3 Normalised compression response for different sands (results from isotropic tests only) 


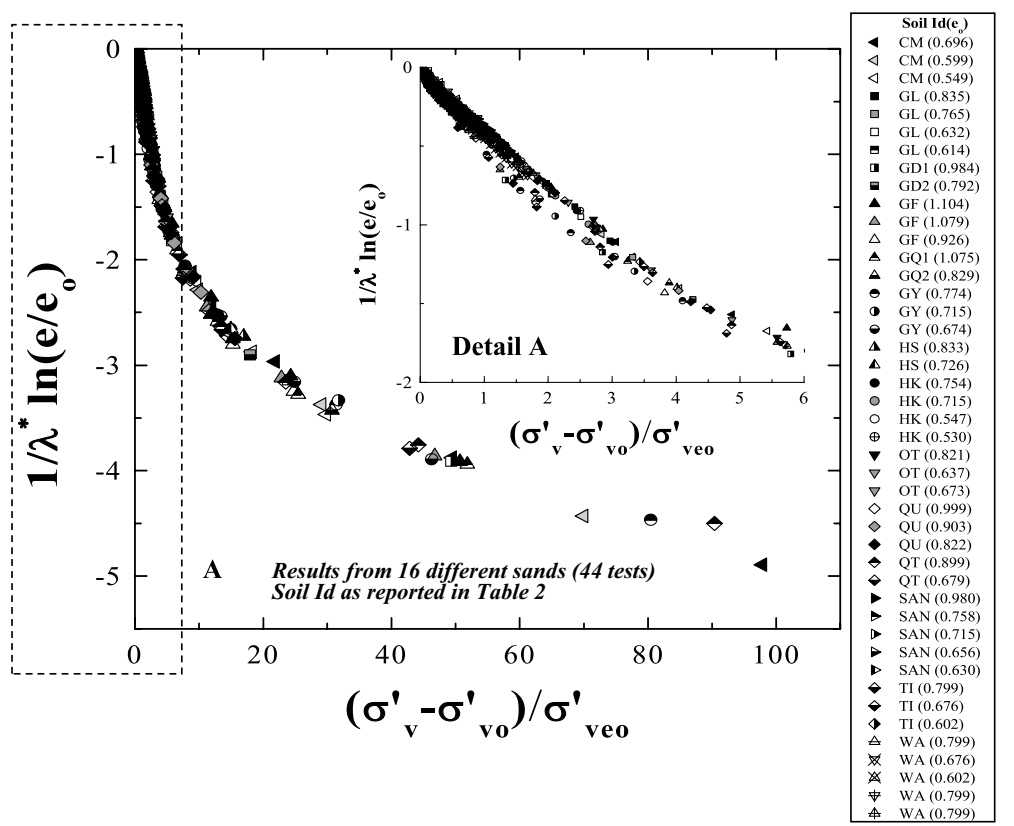

Fig. 4 Normalised compression response for different sands (results from 1-D compression tests: Table 2)

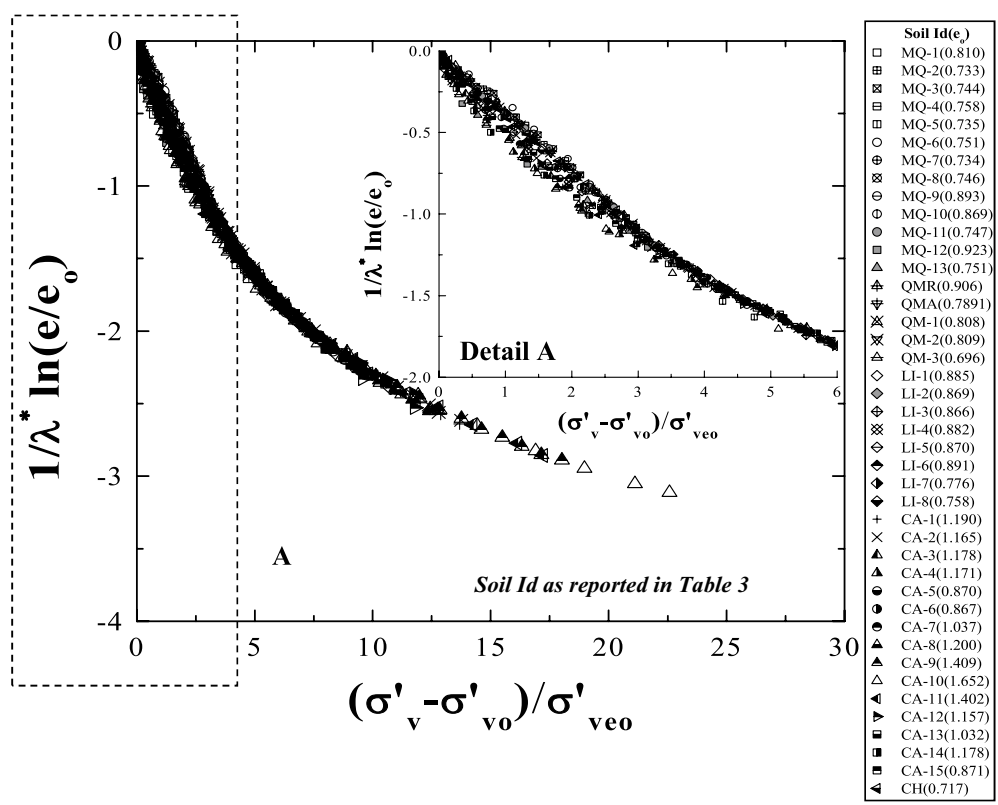

Fig. 5 Normalised compression response for different sands (results from 1-D compression tests: Table 3)

sands and clays so that a unified compression relationship could be developed for both soils.

The experimental results presented above for both sands and clays are replotted in Fig. 8. Although there is some scatter in the results at low stress levels, the overall 


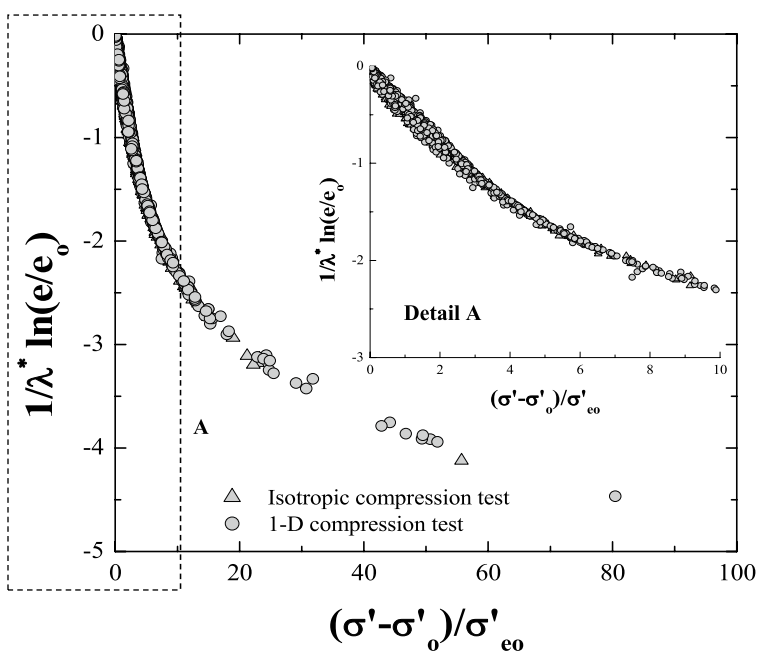

Fig. 6 Normalised compression response of different sands from isotropic and 1-D compression tests

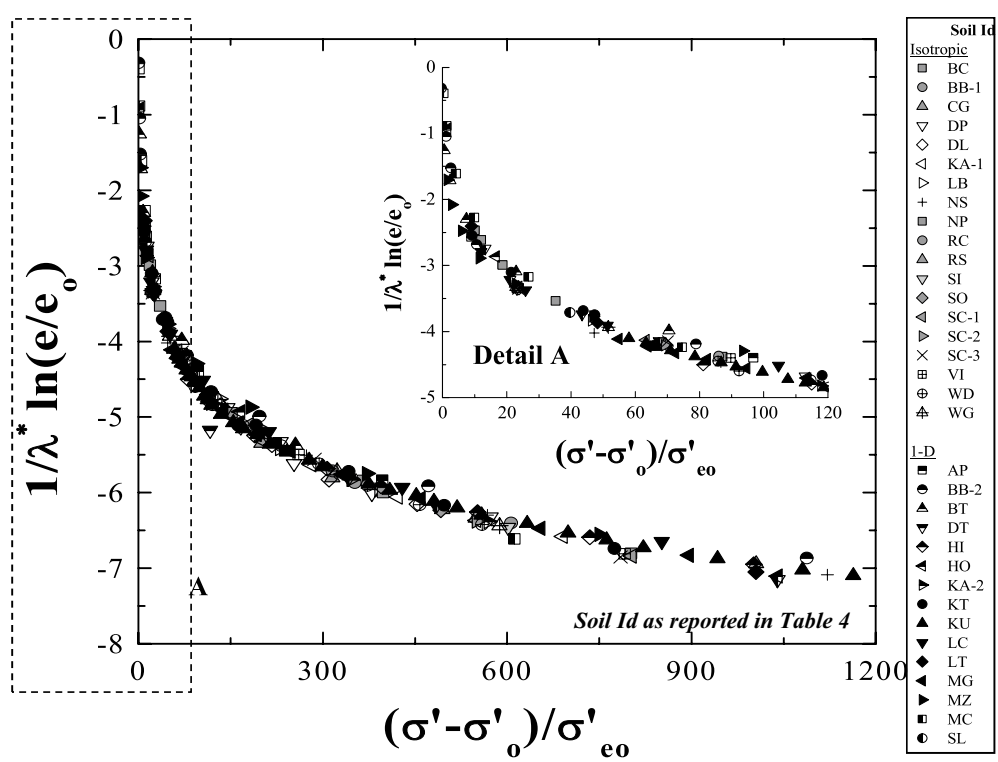

Fig. 7 Normalised compression response for different clays (results from both isotropic and 1-D compression tests)

compression behaviour of all tested sands and clays lie within a narrow range and can be represented uniquely with reasonable accuracy.

\section{The compression line versus the critical state line}

The similarity between the normal compression line (NCL) and critical state line (CSL) for any particular soil is widely reported in the literature. In particular for clay, it is well accepted that the CSL is parallel to the normal consolidation line in the $\ln e-\ell \mathrm{n} p^{\prime}$ space (e.g. $[6,40])$. However, it is difficult to obtain a similar simple relationship for different sands. This is mainly because, unlike for the clays, the CSL for sands is non-linear in the 


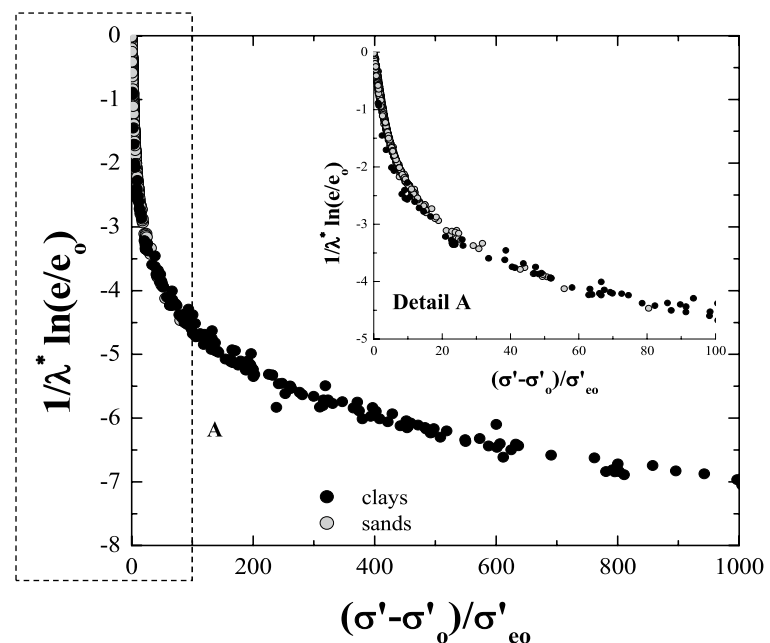

Fig. 8 Unified relationship for normalised compression response for clays and sands

$\ln e-\ln p^{\prime}$ space $([33,40,41])$ and can be represented by a schematic diagram as shown in Fig. 9.

It is envisaged that applying the proposed normalisation scheme to the CSL would be valuable for modelling purposes. Normalising the CSL involves plotting $\left(1 / \lambda^{*}\right) \ln \left(e_{c} / e_{\mathrm{oc}}\right)$ versus $\left(p_{c}^{\prime}-p_{\mathrm{oc}}^{\prime}\right) / p_{\mathrm{eoc}}^{\prime}$, where the various parameters used are the same as for the NCL normalisation, except that they refer to the CSL instead of the NCL, as indicated by the 'c' subscript (see Fig. 9).

The normalisation is examined in Fig. 10, which shows the CSL for different soils varying from clay to soft rocks (reported in Table 5) in a normalised plot. Again, the CSLs for the wide range of soils examined fall within a narrow range and can be represented with reasonable accuracy using an average line passing through the data points.

A direct comparison of the normalised CSL and NCL for the examined soils is presented in Fig. 11 using both the CSL and NCL normalising parameters. It can be clearly observed that all the results fall within a narrow range and can be represented uniquely with reasonable accuracy using the appropriate normalisation for the two lines. This

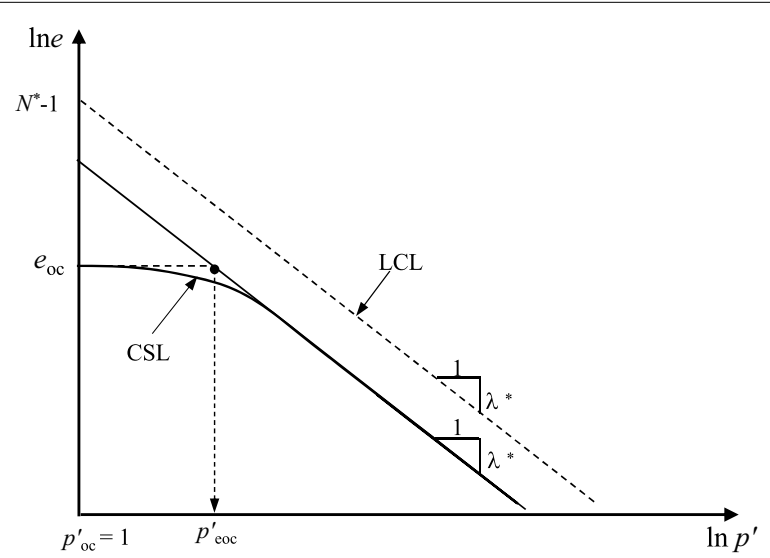

Fig. 9 Idealised critical state line for sands 




Fig. 10 Critical state line for different soils

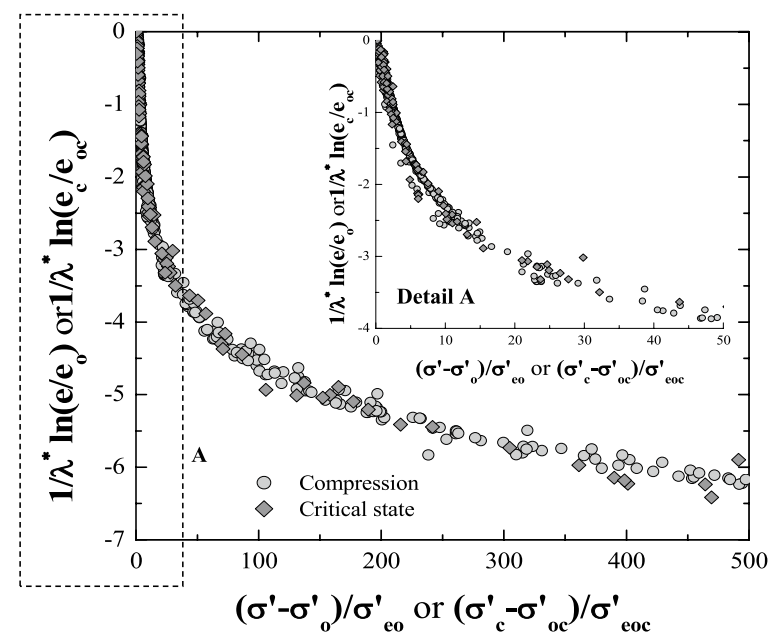

Fig. 11 Compression versus critical state line for different soils in normalised plot

finding is quite important, as it suggests that the general shape of the CSL and NCL is similar for all types of soils in this normalised space, and it can be represented using a similar mathematical form; the difference lies only in the value of the normalising parameters i.e. the initial void ratio $e_{\mathrm{o}}$ for the normal compression line and $e_{\mathrm{c}}$ for the critical state line.

\section{Discussion and areas for further research}

The new normalisation scheme presented above provides a unified framework to describe the compression behaviour of different soils and can be readily implemented for modelling purposes. The method takes into account the initial void ratio $e_{o}$ and the corresponding equivalent stress $\sigma_{\mathrm{eo}}^{\prime}\left(\sigma_{\mathrm{eo}}^{\prime}\right.$ corresponds to $p_{\mathrm{eo}}^{\prime}$ for isotropic tests and $\sigma_{\mathrm{veo}}^{\prime}$ for 
1-D tests) as normalising parameters. In particular, the novelty of the proposed normalisation scheme lies in adopting $\sigma_{\mathrm{eo}}^{\prime}$ as a stress normalising parameter. This stress normalisation is not only consistent with the framework of CSSM, but also can be considered conceptually similar to some of the recent studies on crushability of soils (e.g. [30]).

In addition, it should be noted that $e / e_{\mathrm{o}}$ is a measure of the volumetric strain, which makes the new normalisation scheme more versatile for practical applications and also to develop thermodynamically consistent constitutive models (e.g. [9]), where the volumetric strain (not the void ratio) can only be used as a state variable.

It is a well-known fact that the presence of "structure", either in the form of a fabric or bonding [5], plays an important role in controlling the compression behaviour of natural soils. The results presented in this paper were obtained from reconstituted samples and the new normalisation scheme has been validated only against them. The applicability of the proposed method to structured soil (natural or artificially structured soils) needs further study. However, since the presence of a structure causes the compression curves to move towards the right in the $\ell$ n $e-\ell \mathrm{n} \sigma^{\prime}$ space (e.g. [12]), it can be imagined that the LCL of structured soil needs to be considered in defining the value of $\sigma_{\mathrm{eo}}^{\prime}$. The proposal suggested by Cuccovillo and Coop [12] in defining the compression boundary for structured material could be valuable in this regard.

A unique representation of the NCL and CSL discussed above for different soils is believed to be valuable for developing unified constitutive models within the framework of CSSM and also for proposing unified empirical relationships for different soils. In the case of constitutive modelling, the results presented above can be used to define the yield surface and the hardening rule for different soils. It is also believed to be worth examining the applicability of the new normalisation scheme to develop a unified state boundary surface for different soils.

The proposed normalisation scheme could be used to develop a unified empirical relationship for the qualities that depends on the sand state. For example, since the new normalisation scheme uniquely correlates the void ratio and effective stress for different soils, it may be used to unify the expression used for the small-strain shear modulus of different soils.

\section{Summary and conclusions}

In this paper, a new normalisation scheme is proposed to uniquely represent the compression curves for different soils subjected to different compression loading conditions (1-D or isotropic compression tests). It has been validated against a large number of experimental results extracted from the literature. It is shown that using the new normalisation scheme the compression response of a sand of different initial void ratios can be uniquely represented. Also, by taking into consideration the differences in the compression index between different soils, it is shown that a unique compression curve can be obtained in the normalised plot. The similarities between the compression curves and critical state line are also validated. The new normalisation scheme is consistent with the framework of the CSSM and crushability of soils. The potential applications of the new normalisation scheme to develop unified constitutive and empirical relationship for different soils are also discussed. 


\section{Authors' contributions}

SSS collected and analysed the data and wrote most of the sections of the paper. MAI verified the proposed normalisations scheme, validated the graphs, and wrote some sections of the paper. Both authors read and approved the final manuscript.

\section{Author details}

${ }^{1}$ Fugro, Perth, WA 6009, Australia. ${ }^{2}$ Prince Sultan University, Riyadh, Saudi Arabia.

\section{Acknowledgements}

The work presented in this paper formed part of the research activities of the Centre for Offshore Foundation Systems (COFS), established and supported under the Australian Research Council's Research Centres Program.

\section{Competing interests}

The authors declare that they have no competing interests.

Published online: 25 November 2016

\section{References}

1. Amerasinghe SF (1973) The stress-strain behaviour of clay at low stress levels and high overconsolidation ratio. PhD Thesis, Cambridge University

2. Atkinson JH, Bransby PL (1978) The mechanics of soils. An introduction to critical state soil mechanics. McGraw-Hill, London

3. Been K, Jefferies MG, Hachey J (1991) The critical state of sands. Géotechnique 41(3):365-381

4. Been K, Jefferies MG (1985) A state parameter for sands. Géotechnique 35(2):99-112

5. Burland JB (1990) On the compressibility and shear strength of natural clays. Géotechnique 40(3):329-378

6. Butterfield R (1979) A natural compression law for soils (an advance on e-log p'). Géotechnique 29(4):469-480

7. Chiu HK, Johnston IW (1984) The application of critical state concepts to Melbourne mudstone. In: Proc 4th Australia-New Zealand conf on geomechanics, Perth, vol 1, pp 29-33

8. Chuhan FA, Kjeldstad A, Bjørlykke K, Høeg K (2003) Experimental compression of loose sands: relevance to porosity reduction during burial in sedimentary basins. Can Geotech J 40:995-1011

9. Collins IF, Kelly PA (2002) A thermomechanical analysis of a family of soil models. Géotechnique 52(7):507-518

10. Coop MR, Lee IK (1993) The behaviour of granular soils and elevated stresses. In: Proc of wroth memorial symposium: predictive soil mechanics, London, pp 186-198

11. Coop MR (1990) The mechanics of uncemented carbonate sands. Géotechnique 40(4):607-626

12. Cuccovillo T, Coop MR (1999) On the mechanics of structured sands. Géotechnique 49(6):741-760

13. Den Hann EJ (1992) The formulation of virgin compression of soils. Géotechnique 42(3):465-583

14. DeSouza JM (1958) Compressibility of quartz sand at high pressure. M.Sc. thesis, Massachusetts Institute of Technology, USA

15. Gerogiannopoulos N, Brown ET (1978) The critical state concept applied top rock. Int J Rock Mech Min Sci 15:1-10

16. Hendron AJ (1963) The behaviour of sand is one-dimensional compression. PhD thesis, University of Illinois at Urbana, USA

17. Huang JT (1994) The effect of density and cementation on cemented sands. PhD thesis, University of Sydney, Australia

18. Hvorslev MJ (1937). Physical properties of remoulded cohesive soils. Translation 69-5, US Waterways Experiment Station, Vicksburg, MISS. (translation published in 1969)

19. Hyodo M, Nakata Y, Yoshimoto N, Hyde AFL (2003) The role of fines in the flow deformation and liquefaction of a volcanic soil Shirashu. In: Di Benedetto H, Doanh T, Geoffroy H, Sauzéat C, Balkema AA (eds) Proc 3rd int conf on deformation characteristics of geomaterials, France, pp 721-727

20. Ismail MA (2000) Strength and deformation behaviour of calcite-cemented calcareous soils. PhD thesis, University of Western Australia, Australia

21. Ishihara K, Tatsuoka F, Yasuda S (1975) Undrained deformation and liquefaction of sand under cyclic stress. Soils Found 15(1):29-44

22. Jefferies M, Been K (2000) Implications for critical state theory from isotropic compression of sand. Géotechnique 50(4):419-429

23. Jennings JEB, Burland JB (1962) Limitations to the use of effective stress in partly saturated soils. Géotechnique 12(2):125-145

24. Kato Y, Nakata Y, Hyodo M, Murata H (2003) Effect of particle characteristics on drained shear properties of sand. In: Di Benedetto H, Doanh T, Geoffroy H, Sauzéat C, Balkema AA (eds) Proc 3rd int conf on deformation characteristics of geomaterials, France, pp 707-713

25. Konrad J-M (1998) Sand state from cone penetrometer tests: a framework considering grain crushing stress. Géotechnique 48(2):201-215

26. Lambe TW, Whitman RV (1969) Soil mechanics. Wiley, New York

27. Lee KL, Seed HB (1967) Drained strength characteristics of sands. J Soil Mech Found Div. 93(6):117-141

28. Leonards GA, Ramiah BK (1960) Time effect in the consolidation of clays. ASTM Spec Tech Publ 254:116-130

29. Li XS, Wang Y (1998) Linear representation of steady-state line for sands. J Geotech Geoenviron Eng 124(12):1215-1217

30. Mcdowell GR, Bolton MD (1998) On the micromechanics of crushable aggregates. Géotechnique 48(5):667-679 
31. Mesri G, Rokshar A, Bohor BF (1975) Composition and compressibility of typical samples of Mexico City clay. Géotechnique 25(3):527-554

32. Michelis P, Brown ET (1986) A yield equation for rock. Can Geotech J 23:9-17

33. Miura N, Murate H, Yasufuku N (1984) Stress-strain characteristics of sand in a particle crushing region. Soils Found 24(1):77-89

34. Moriwaki T, Umehara K, Horiuchi K, Yoshikuni, H (2000) The coefficient of permeability of clays determined from permeability tests and consolidation test. In: Nakase A, Tsuchida T (eds) Proc Int Sym—IS Yokohama pp 83-88

35. Muir Wood D (1990) Soil behaviour and critical state soil mechanics. Cambridge University Press, New York

36. Nadarajah V (1973) Stress-strain properties of lightly overconsolidated clays. PhD thesis, Cambridge University, UK

37. Nagaraj TS, Srinivasa Murthy BR (1986) A critical reappraisal of compression index equations. Géotechnique 36(1):27-32

38. Novello EA, Johnston IW (1995) Geotechnical materials and the critical state. Géotechnique 45(2):223-235

39. Pestana JM, Whittle AJ (1995) Compression model for cohessionless soils. Géotechnique 45(4):611-631

40. Pestana JM (1994) A unified constitutive model for clays and sands. ScD thesis, Massachusetts Institute of Technology, USA

41. Riemer MF, Seed RB, Nicholson PG, Jong HL (1990) Steady state testing of loose sands: limiting minimum density. J Geotech Eng 116(2):332-337

42. Roberts JE (1964) Sand compression as a factor in oil field subsidence. PhD thesis, Massachusetts Institute of Technology, USA

43. Roscoe KH, Schofield AN, Wroth CP (1958) On the yielding of soils. Géotechnique 8(1):22-53

44. Schofield AN, Wroth CP (1968) Critical state soil mechanics. McGraw-Hill, London

45. Sharma SS (2004). Characterisation of cyclic behaviour of calcite cemented calcareous soils. PhD thesis, University of Western Australia, Australia

46. Smith PR, Jardine RJ, Hight DW (1992) The yielding of Bothkennar clay. Géotechnique 42(2):257-274

47. Taylor DW (1948) Fundamental of soil mechanics. Wiley, New York

48. Vesic AS, Clough GW (1968) Behaviour of granular materials under high stresses. J Soil Mech Found Div 94(3):661-688

49. Yamamuro JA, Bopp PA, Lade PV (1996) One-dimensional compression of sands at high pressure. J Geotech Eng 122(2):147-154

\section{Submit your manuscript to a SpringerOpen ${ }^{\circ}$ journal and benefit from:}

- Convenient online submission

- Rigorous peer review

- Immediate publication on acceptance

- Open access: articles freely available online

- High visibility within the field

- Retaining the copyright to your article

Submit your next manuscript at $\boldsymbol{\nabla}$ springeropen.com 